\title{
Testing for higher-order correlations in massively parallel spike
} trains

\author{
Benjamin Staude*1, Stefan Rotter ${ }^{2,3}$ and Sonja Grün ${ }^{1,4}$
}

\author{
Address: ${ }^{1}$ Computational Neuroscience Group, Brain Science Institute, RIKEN, Wako, Japan, ${ }^{2}$ Theory and Data Analysis, Institute for Frontier Areas \\ of Psychology and Mental Health. Freiburg, Germany, ${ }^{3}$ Bernstein Center for Computational Neuroscience Freiburg, Germany and ${ }^{4}$ Bernstein \\ Center for Computational Neuroscience Berlin, Germany \\ Email: Benjamin Staude* - staude@brain.riken.co.jp \\ * Corresponding author
}

from Sixteenth Annual Computational Neuroscience Meeting: CNS*2007

Toronto, Canada. 7-12 July 2007

Published: 6 July 2007

BMC Neuroscience 2007, 8(Suppl 2):P26 doi:10.I I86/I47|-2202-8-S2-P26

(c) 2007 Staude et al; licensee BioMed Central Ltd.

The cell assembly hypothesis [1] postulates dynamically interacting groups of neurons as building blocks of cortical information processing. Synchronized spiking across large neuronal groups was later suggested as a potential signature for active assemblies [2], resulting in specific higher-order correlations among assembly members. Mathematical concepts for the treatment of higher-order correlations in massively parallel spike trains have been suggested in the past, but, due to constraints of insufficient sample sizes, estimation of higher-order parameters from recorded data poses serious problems [3]. As a consequence, most attempts to detect active cell assemblies resort to pairwise interactions. However, pairwise approaches do not imply the presence of higher-order effects in large neuronal populations and are not sensitive for sparse synchronous events [4]. The limited experimental evidence in favor of the cell assembly hypothesis must to a large extent be assigned to the lack of suitable analysis tools [5]. Massively parallel extracellular recordings, in contrast, are nowadays widely available.

Here we present a novel procedure that allows us to detect higher-order correlations in binned (filtered) multi-unit spike trains. Based on estimates of only a few low-order cumulants of such signals we can devise a test for the presence of higher-order correlations in the observed neuronal population. The method circumvents the need to estimate large numbers of higher-order parameters and, therefore, is less susceptible than previous approaches to the problems associated with limited sample sizes from in vivo recordings $[3,4]$. The method was tested for correlated Poisson processes where correlations of various orders were induced by 'inserting' appropriate patterns of nearsynchronous spikes [6]. When applied to simulated data, the test was found to be surprisingly sensitive, even for cases where the effect of the higher-order patterns on pairwise correlation coefficients $c$ were negligible (in the range of $c \sim 0.01$, see [4]).

We present our test for rectangular filters that mimic the binning and/or counting that is usually applied to extracellular spike recordings. We discuss applications with other types of filters that could make the proposed test applicable for other signal types, e.g. intracellular membrane potentials. Furthermore, the sensitivity and reliability of the new method for data, where the Poisson assumptions are not strictly satisfied, is critically discussed.

\section{References}

I. Hebb DO: The organization of behavior: A neuropsychological theory. Wiley, New York; 1949.

2. Abeles M: Corticonics. Cambridge University Press, Cambridge; 1991.

3. Martignon L, Von Hasseln H, Grün S, Aertsen A, Palm G: Detecting higher-order correlations among the spiking events in a group of neurons. Biol Cybern 1995, 73:69-8I.

4. Schneidman E, Berry MJ II, Segev R, Bialek W: Weak pairwise correlations imply strongly correlated network states in a neural population. Nature 2006, 440:1007-1012. 
5. Brown EN, Kass RE, Mithra PP: Multiple neural spike train data analysis: state-of-the-art and future challenges. Nat Neurosci 2004, 7:456-46I.

6. Kuhn A, Aertsen A, Rotter S: Higher-order statistics of input ensembles and the response of simple model neurons. Neural Comput 2003, 15:67-101.

Publish with Bio Med Central and every scientist can read your work free of charge

"BioMed Central will be the most significant development for disseminating the results of biomedical research in our lifetime. " Sir Paul Nurse, Cancer Research UK

Your research papers will be:

- available free of charge to the entire biomedical community

- peer reviewed and published immediately upon acceptance

- cited in PubMed and archived on PubMed Central

- yours - you keep the copyright

Submit your manuscript here:

http://www.biomedcentral.com/info/publishing_adv.asp 